\title{
ATRIBUTOS MICROBIANOS DO SOLO APÓS A ADIÇÃO DE LODO ANAERÓBIO DA ESTAÇÃO DE TRATAMENTO DE EFLUENTES DE PARBOILIZAÇÃO DO ARROZ ${ }^{(1)}$
}

\author{
Giúlia D’Avila Vieira ${ }^{(2)}$, Danilo Dufech Castilhos $^{(3)} \&$ Rosa Maria \\ Vargas Castilhos ${ }^{(3)}$
}

\begin{abstract}
RESUMO
O cultivo do arroz é destaque na região Sul, com 60 \% da produção total desse cereal no país. A parboilização do arroz é um tratamento hidrotérmico que cozinha parcialmente os grãos ainda em casca, melhorando seu valor nutricional. Desse processo resulta um efluente rico em matéria orgânica e nutrientes, que pode ser utilizado como adubo orgânico na agricultura. O presente trabalho objetivou avaliar a qualidade de um solo com base nas alterações de alguns atributos microbianos decorrentes do acréscimo de lodo anaeróbio da estação de tratamento de efluentes de parboilização do arroz. Foram realizados dois experimentos, sendo o primeiro em casa de vegetação, por meio do cultivo de milho em um Argissolo acrescido de lodo (base seca) nas doses de 2,$15 ; 4,31 ; 8,62 ; 12,93 ;$ e 17,24 $\mathrm{g} \mathrm{kg}^{-1}$, em que foram analisados os teores de C orgânico total (COT) e N total (NT) do solo e da biomassa microbiana. $\mathrm{O}$ segundo foi desenvolvido em laboratório, utilizando-se vasos respirométricos, com o mesmo solo e tratamentos do experimento anterior, onde se analisou a atividade da microbiota do solo pela determinação da respiração basal. Como tratamentos controle foram utilizados: solo sem adubação e solo adubado com NPK. Os tratamentos foram dispostos em delineamento completamente casualizado com quatro repetições. A atividade microbiana do solo e o C (CM) e N (NM) da biomassa microbiana aumentaram com as doses de lodo e proporcionaram diminuição no quociente metabólico do solo. A aplicação do lodo não alterou as relações COT/NT, CM/NM, CM/COT e NM/NT, em comparação com o tratamento NPK. A aplicação do lodo ao solo aumentou os teores de COT e causou diminuição nos teores de $\mathrm{N}$ mineral $\left(\mathrm{NH}_{4}{ }^{+} \mathbf{e} \mathrm{NO}_{3}{ }^{-}\right)$, quando comparados aos do tratamento NPK. O lodo originado da parboilização do arroz pode ser aplicado ao solo, em doses recomendadas, com benefícios à atividade e à biomassa microbiana.
\end{abstract}

Termos de indexação: C orgânico, nitrogênio do solo, respiração basal, biomassa microbiana.

\footnotetext{
(1) Parte da Dissertação de Mestrado do primeiro autor. Recebido para publicação em agosto de 2009 e aprovado em janeiro de 2011.

(2) Professora do Instituto Federal Sul Rio-Grandense - IFSul. Praça Vinte de Setembro 455, Centro, CEP 96015-360 Pelotas (RS). E-mail: giulia_vieira@yahoo.com.br

(3) Professores Associados do Departamento de Solos, Universidade Federal de Pelotas - PPGA/UFPel. Caixa Postal 354, CEP 96010-900 Pelotas (RS). Email: danilodc@ufpel.tche.br
} 


\title{
SUMMARY: SOIL MICROBIAL ATTRIBUTES AFTER APPLICATION OF ANAEROBIC SLUDGE FROM A SEWAGE TREATMENT STATION OF PARBOILED RICE
}

\begin{abstract}
Rice, grown in all Brazilian regions, is particularly important in the southern region, where $60 \%$ of the total production of this cereal is raised. The rice parboiling process is a hydrothermal treatment of partially cooking the grains in the husk, improving the nutritional value. This process results in an effluent rich in organic matter and nutrients, which can be used as organic fertilizer in agriculture. In this sense, this study aimed to evaluate the quality of a soil based on changes of some microbial properties arising from the addition of anaerobic sludge from an effluent treatment plant of parboiled rice. Two experiments were conducted. The first in a greenhouse, with corn grown on an Ultisol enriched with anaerobic sludge of parboiling rice at doses of: $2.15 ; 4.31 ; 8.62 ; 12.93$; and $17.24 \mathrm{~g} \mathrm{~kg}^{-1}$. Soil organic carbon and nitrogen and the microbial biomass were evaluated. The second experiment was developed in the laboratory using respirometric vessels with the same soil and treatments as in the previous experiment; the microbial activity was determined by basal respiration. Soil without fertilization and NPK fertilized soil constituted control treatments. Treatments were arranged in a completely randomized design with four replications. The sludge increased soil microbial activity, and the carbon and nitrogen contents of the microbial biomass, and decreased the soil metabolic quotient. Sludge application did not affect the ratios COT/NT, CM/NM, CM/ COT and NM/NT in comparison to the NPK treatment. Sludge increased the contents of soil organic carbon and caused a decrease in the levels of mineral $\mathrm{N}\left(\mathrm{NH}_{4}^{+}\right.$and $\left.\mathrm{NO}_{3}{ }^{-}\right)$, compared to the NPK treatment. The sludge originated from rice parboiling can be applied to soil at the recommended doses, with benefits for the microbial activity and biomass.
\end{abstract}

Index terms: organic carbon, soil nitrogen, basal respiration, microbial biomass.

\section{INTRODUÇÃO}

Os microrganismos possuem a capacidade de dar respostas rápidas a mudanças nos atributos microbianos do solo - característica que não é observada nos indicadores químicos ou físicos. Em alguns casos, as alterações na biomassa e, ou, na atividade microbiana podem refletir um claro sinal na melhoria ou na degradação do solo.

A biomassa microbiana é definida como o componente vivo da matéria orgânica do solo, excluindo-se a macrofauna e as raízes das plantas. A proporção de células microbianas vivas contendo C (C-microbiano) geralmente compreende de 1 a $5 \%$ do $\mathrm{C}$ orgânico total (COT), enquanto para o N (Nmicrobiano) compreende de 1 a $6 \%$ do $\mathrm{N}$ total (NT) (Jenkinson \& Ladd, 1981). Isoladamente, a biomassa microbiana pouco reflete as alterações nos atributos microbianos do solo (Brookes, 1995), porém a biomassa microbiana associada ao conteúdo de matéria orgânica pode ser utilizada como índice para comparar a atributos microbianos do solo sob diferentes manejos.

A avaliação da respiração do solo, medida pela oxidação biológica da matéria orgânica a $\mathrm{CO}_{2}$ pelos microrganismos aeróbios, é a técnica mais frequente para quantificar a atividade microbiana. Pode ser determinada pela produção de $\mathrm{CO}_{2}$ ou pelo consumo de $\mathrm{O}_{2}$ em um ecossistema, sendo positivamente relacionada com o conteúdo de matéria orgânica e com a biomassa microbiana (Alef \& Nannipieri, 1995). A combinação das medidas da respiração do solo com a biomassa microbiana fornece a quantidade de $\mathrm{CO}_{2}$ evoluída por unidade de biomassa, denominada quociente metabólico ou respiratório $\left(q \mathrm{CO}_{2}\right)$. $\mathrm{O} q \mathrm{CO}_{2}$ indica a eficiência da biomassa microbiana em utilizar o C disponível para biossíntese, sendo sensível indicador para estimar a atividade biológica e a qualidade do substrato (Anderson \& Domsch , 1990).

As mudanças no sistema de manejo do solo que incluem a aplicação de lodos urbanos e industriais têm proporcionado alterações nas propriedades biológicas do solo. Araújo \& Monteiro (2006) relatam que a aplicação de lodo de indústria têxtil não compostado causou efeitos negativos na biomassa microbiana do solo. Já o mesmo lodo compostado teve efeitos positivos na biomassa, na atividade microbiana e no número de bactérias, melhorando a capacidade de reciclagem do C. Cardoso \& Fortes (2000) avaliaram a efeito do uso de lodo de esgoto sobre a microbiota do solo e constataram aumentos na respiração basal (liberação de $\mathrm{CO}_{2}$ ) e no quociente metabólico do solo, ao passo que a biomassa microbiana permaneceu inalterada. A medição do C liberado pela atividade microbiana do solo, denominada respiração basal, tem sido empregada na avaliação da mineralização dos compostos orgânicos (Brookes, 1995). Dessa forma, o estudo da mineralização da carga orgânica de lodos, quando aplicados ao solo, pode nortear a definição da dose a ser usada em campo, que não prejudique a atividade microbiana.

A aplicação de lodos urbanos ou industriais ao solo pode provocar alterações na estrutura e no 
funcionamento do agroecossistema, sendo a comunidade microbiana um dos componentes mais sensíveis para utilização como indicadora da qualidade dos solos (Dick, 1994; Giller et al., 1998). A aplicação desses materiais pode tanto estimular a atividade microbiana do solo, devido ao aumento de $\mathrm{C}$ e nutrientes disponíveis, como inibir, em razão da presença de metais pesados e outros poluentes (Paula et al., 2006 ). Portanto, o comportamento da população microbiana depende da qualidade e da quantidade desses resíduos aplicados ao solo.

Estudos sobre o uso agrícola de lodos industriais, como o originado do processo de parboilização do arroz, são indispensáveis para o conhecimento das alterações decorrentes. O presente trabalho teve como objetivo avaliar alguns atributos químicos e microbianos que conferem qualidade ao solo após a adição de um lodo anaeróbio da estação de tratamento de efluentes da parboilização do arroz.

\section{MATERIAL E MÉTODOS}

No presente estudo foi utilizada a camada de 0 $20 \mathrm{~cm}$ de um Argissolo Vermelho-Amarelo PAD (Embrapa, 1999) coletado na Estação Experimental da Palma da UFPel. Amostras do lodo anaeróbio da parboilização do arroz foram coletadas em três empresas de beneficiamento do município de Pelotas/ RS: Ehlert Indústria e Comércio Ltda, Krolow Beneficiamento de Arroz e Indústria Nelson Wendt Cia. Observou-se que a variação dos parâmetros físicoquímicos dessas amostras foi pequena, em razão das poucas diferenças no processamento de parboilização, da mesma região e do mesmo sistema de fertilização da cultura. Optou-se pela utilização do lodo produzido na indústria de beneficiamento de arroz Nelson Wendt, cujas características físicas e químicas, em conjunto com os dados do solo, encontram-se no quadro 1.
O primeiro experimento foi conduzido utilizandose, como unidades experimentais, vasos plásticos com capacidade para $4,0 \mathrm{~kg}$ de solo. Os tratamentos estudados foram: 1 - testemunha; 2- adubação NPK; 3- 2,15, 4- 4,31, 5- 8,62, 6- 12,93 g, e 7- 17,24 g kg-1 de de solo de lodo anaeróbio de parboilização (base seca).

As doses de NPK foram determinadas de acordo com a análise química do solo, utilizando-se a recomendação da Comissão de Química e Fertilidade do Solo/NRS (CQFS/NRS, 2004) para a cultura do milho. Foram aplicados, em $\mathrm{mg} \mathrm{kg}^{-1}$ de solo: 128 de N (ureia), 180 de P (superfosfato triplo) e 100 de K (cloreto de potássio). O lodo obtido para realização deste trabalho apresentou baixo poder de neutralização da acidez (Quadro 1). Devido a isso, e para garantia da elevação do $\mathrm{pH}$ do solo a 6,0, aplicou-se calcário em todos os tratamentos na forma de $\mathrm{CaCO}_{3}+\mathrm{MgCO}_{3}$ (2:1), na dose de $1,12 \mathrm{~g} \mathrm{~kg}^{-1}$. As doses dos tratamentos 3, 4, 5, 6 e 7 foram calculadas após a determinação do teor de $\mathrm{N}$ do lodo, aplicando-se, respectivamente, 25, 50, 100, 150 e $200 \%$ da quantidade de lodo necessária para atender à exigência de $\mathrm{N}$ da cultura do milho, conforme a Comissão de Química e Fertilidade do Solo/ NRS (CQFS/NRS, 2004), o que equivaleu a 4,3, 8,6, $17,2,25,9$ e $34,5 \mathrm{Mg} \mathrm{ha}^{-1}$ do lodo.

Após a aplicação e mistura dos tratamentos com o solo, semeou-se milho, cultivar BM 2202-Biomatrix híbrido, que foi desbastado após 10 dias da semeadura, mantendo-se duas plantas por vaso. O experimento foi disposto em um delineamento completamente casualizado com quatro repetições, num total de 28 unidades.

Os vasos foram irrigados diariamente com quantidade de água destilada, procurando-se manter a umidade equivalente à retenção de 0,03 MPa. Esse procedimento foi efetuado pesando-se diariamente cada vaso e repondo a quantidade de água necessária para manutenção da umidade do solo proposta.

\section{Quadro 1. Características físicas e químicas do solo, antes do experimento, e do lodo utilizado}

\begin{tabular}{|c|c|c|c|}
\hline Solo $^{(1)}$ & Concentração & $\operatorname{Lodo}^{(1)}$ & Concentração \\
\hline Argila $\left(\mathrm{g} \mathrm{kg}^{-1}\right)$ & 230 & Umidade $\left(\mathrm{g} \mathrm{kg}^{-1}\right)$ & 952 \\
\hline $\mathrm{pH} \mathrm{H} \mathrm{H}_{2} \mathrm{O}$ & 4,7 & $\mathrm{pH}\left(\mathrm{H}_{2} \mathrm{O}\right)$ & 8,5 \\
\hline pH SMP & 6,2 & Poder de Neutralização (\%) & 7,0 \\
\hline Carbono orgânico $\left(\mathrm{g} \mathrm{kg}^{-1}\right)$ & 7,0 & Carbono orgânico $\left(\mathrm{g} \mathrm{kg}^{-1}\right)$ & 157,5 \\
\hline Fósforo $\left(\mathrm{mg} \mathrm{dm}^{-3}\right)$ & 3,7 & Fósforo $\left(\mathrm{g} \mathrm{kg}^{-1}\right)$ & 42,4 \\
\hline Potássio $\left(\mathrm{mg} \mathrm{dm}^{-3}\right)$ & 30 & Potássio $\left(\mathrm{g} \mathrm{kg}^{-1}\right)$ & 16,0 \\
\hline Cálcio $\left(\mathrm{cmol}_{\mathrm{c}} \mathrm{dm}^{-3}\right)$ & 0,6 & Cálcio $\left(\mathrm{g} \mathrm{kg}^{-1}\right)$ & 68,4 \\
\hline Magnésio $\left(\mathrm{cmol}_{\mathrm{c}} \mathrm{dm}^{-3}\right)$ & 0,4 & Magnésio ( $\mathrm{g} \mathrm{kg}^{-1}$ ) & 84,7 \\
\hline Sódio $\left(\mathrm{mg} \mathrm{dm}^{-3}\right)$ & 11 & Nitrogênio $\left(\mathrm{g} \mathrm{kg}^{-1}\right.$ ) & 23,51 \\
\hline \multirow[t]{4}{*}{ Alumínio $\left(\mathrm{cmol}_{\mathrm{c}} \mathrm{dm}^{-3}\right)$} & 1,8 & Cobre $\left(\mathrm{mg} \mathrm{kg}^{-1}\right)$ & 84 \\
\hline & & Zinco $\left(\mathrm{g} \mathrm{kg}^{-1}\right)$ & 1,7 \\
\hline & & Ferro $\left(\mathrm{g} \mathrm{kg}^{-1}\right)$ & 7,1 \\
\hline & & Manganês ( $\mathrm{g} \mathrm{kg}^{-1}$ ) & 31,0 \\
\hline
\end{tabular}

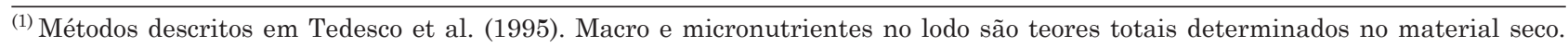


Após 41 dias de cultivo de milho, o solo de cada unidade foi destorroado e peneirado $(4 \mathrm{~mm})$, sendo retiradas amostras, as quais foram mantidas em geladeira, com temperatura aproximada de $4{ }^{\circ} \mathrm{C}$, para análises microbiológicas. Os teores de $\mathrm{C}$ e de $\mathrm{N}$ da biomassa microbiana foram determinados com base no método descrito por Vance et al. (1987). Entretanto, para eliminação dos microrganismos, substituiu-se a fumigação com clorofórmio pela irradiação em forno de micro-ondas a $2.450 \mathrm{MHz}$, durante $4 \mathrm{~min}$ (Ferreira et al., 1999). As relações CBM/COT e NBM/NT foram obtidas pelas razões entre o $\mathrm{C}$ da biomassa microbiana (CBM) e o C orgânico total do solo (COT) e entre o N da biomassa microbiana (NBM) e o $\mathrm{N}$ total (NT) do solo. Para a análise de $\mathrm{C}$ orgânico total, $\mathrm{N}$ total e Nmineral $\left(\mathrm{NO}_{3}{ }^{-}\right.$e $\left.\mathrm{NH}_{4}{ }^{+}\right)$do solo, amostras de solo foram secas ao ar, peneiradas $(2 \mathrm{~mm})$ e analisadas segundo método descrito por Tedesco et al. (1995).

$\mathrm{O}$ segundo experimento foi desenvolvido em laboratório. Amostras de $100 \mathrm{~g}$ de solo, acrescidas dos mesmos tratamentos do experimento anterior, foram acondicionadas em vasos respirométricos, para análise da respiração basal (RB). A respiração foi avaliada de $10 \mathrm{em} 10$ dias pela captação do $\mathrm{C}-\mathrm{CO}_{2}$ liberado em uma solução de $\mathrm{NaOH} 1 \mathrm{~mol} \mathrm{~L}^{-1}$, que posteriormente foi titulada com solução de $\mathrm{HCl}$ $1 \mathrm{~mol} \mathrm{~L}^{-1}$, conforme o método de Stotzky (1965). O $\mathrm{CO}_{2}$ de cada medição foi somado com o da medição anterior, avaliando-se o total acumulado de cada tratamento ao final de 59 dias de incubação. A quantidade de $\mathrm{CO}_{2}$ liberada em cada tratamento e período de avaliação foi calculada conforme a equação 1 e expressa em mg $100 \mathrm{~g}^{-1} \mathrm{C}-\mathrm{CO}_{2}$.

$$
\mathrm{RB}=(\mathrm{VPB}-\mathrm{VA}) \times \mathrm{M} \text { ácido } \times \mathrm{Eq} . \mathrm{C}-\mathrm{CO}_{2}
$$

em que $\mathrm{VPB}=$ volume de $\mathrm{HCl}$ gasto na prova em branco; $\mathrm{VA}=$ volume de $\mathrm{HCl}$ gasto na amostra; $\mathrm{M}$ ácido = concentração do $\mathrm{HCl}$; e Eq. $\mathrm{C}-\mathrm{CO}_{2}=$ equivalente grama do $\mathrm{C}-\mathrm{CO}_{2}$.

A quantidade de $\mathrm{C}$ biodegradado total foi estimada multiplicando-se o total de $\mathrm{CO}_{2}$ liberado por 1,5, de modo que incluísse também a quantidade de $\mathrm{C}$ assimilada pela microbiota, que corresponde à metade do $\mathrm{C}$ orgânico oxidado e liberado como $\mathrm{CO}_{2}$ (Prosser, 2007).

A taxa de respiração por unidade de biomassa ou quociente metabólico $\left(\mathrm{qCO}_{2}\right)$ foi obtida pela relação entre a taxa de respiração basal, que consiste na medida da produção de $\mathrm{CO}_{2}$, resultante da atividade metabólica do solo, e a biomassa microbiana (Anderson \& Domsch, 1990).

Os dados foram submetidos à análise de variância e ao teste de médias Duncan a 5 \% para comparação do tratamento NPK com as doses do lodo e regressão polinomial, utilizando o programa estatístico Winstat (Machado, 2001).

\section{RESULTADOS E DISCUSSÃO}

\section{Carbono orgânico total do solo}

A aplicação de lodo anaeróbio da estação de tratamento de efluentes da parboilização de arroz provocou aumentos significativos no teor de $\mathrm{C}$ orgânico do solo, quando comparado à testemunha e ao tratamento NPK (Figura 1). O aumento no teor de C orgânico é consequência do seu acréscimo com a aplicação do lodo, uma vez que as doses dos tratamentos $1,2,3,4$ e 5 incorporaram 1,$29 ; 2,58 ; 5,16 ; 7,74$; e $10,32 \mathrm{~g} \mathrm{~kg}^{-1}$ de $\mathrm{C}$, respectivamente. Não foram detectadas diferenças significativas entre as doses aplicadas do lodo, provavelmente devido à mineralização crescente do $\mathrm{C}$ aplicado ao solo via lodo de parboilização. Trabalhos realizados por Vaz \& Gonçalves (2002) e Lambais \& Carmo (2008) mostraram que os efeitos de lodos como o de esgoto sobre o C orgânico dos solos são temporários, pois sua adição estimula a atividade microbiana, a qual atua sobre frações orgânicas de fácil decomposição, causando diminuição nos teores de matéria orgânica e aumentando o teor de $\mathrm{C}$ e $\mathrm{N}$ na microbiota do solo. Segundo Bettiol \& Fernandes (2004), em estudo realizado com plantas de milho, a aplicação de lodo de esgoto também resultou em maior acúmulo de $\mathrm{C}$ no solo.

\section{Nitrogênio mineral}

Os maiores teores de $\mathrm{N}$ mineral total $\left(\mathrm{NH}_{4}{ }^{+}+\mathrm{NO}_{3}{ }^{-}\right)$ e de $\mathrm{NH}_{4}{ }^{+}$foram observados com a aplicação de NPK, provavelmente devido à disponibilidade imediata do N nesse tratamento (Quadro 2). Esse tratamento apresentou teores de $\mathrm{N}$ mineral significativamente superiores aos do tratamento testemunha e aos de todas as doses do lodo aplicadas.

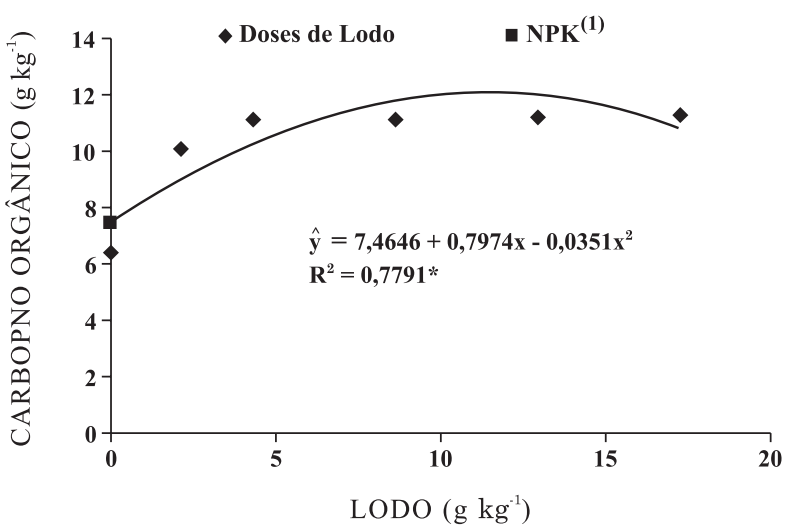

Figura 1. Variação dos teores de $\mathrm{C}$ orgânico total no solo em função da aplicação do lodo anaeróbio da estação de tratamento de efluentes de parboilização de arroz. "Significativo a 5 \%.(1) Tratamento NPK incluído como referência fora da análise de regressão. 
Quadro 2. Teores de $\mathrm{N}\left(\mathrm{NH}_{4}^{+}+\mathrm{NO}_{3}^{-}\right), \mathrm{N}_{-} \mathrm{NH}_{4}^{+}$e $\mathrm{N}-\mathrm{NO}_{3}^{-}$ do solo após 59 dias de incubação com a aplicação de lodo anaeróbio da estação de tratamento de efluentes da parboilização de arroz

\begin{tabular}{lrll}
\hline Tratamento & $\mathbf{N H}_{4}{ }^{+}+\mathbf{N O}_{3}{ }^{-}$ & $\mathbf{N H}_{4}{ }^{+}$ & $\mathbf{N O}_{3}{ }^{-}$ \\
\cline { 2 - 4 } & \multicolumn{3}{c}{$\mathrm{mg} \mathrm{kg}^{-1}$} \\
Testemunha & $4,03 \mathrm{~d}$ & $3,46 \mathrm{~d}$ & $0,57 \mathrm{~d}$ \\
NPK & $35,32 \mathrm{a}$ & $25,81 \mathrm{a}$ & $9,51 \mathrm{a}$ \\
Lodo 1 & $8,41 \mathrm{~d}$ & $3,67 \mathrm{~d}$ & $4,74 \mathrm{~b}$ \\
Lodo 2 & $6,97 \mathrm{~d}$ & $2,79 \mathrm{~d}$ & $4,18 \mathrm{bc}$ \\
Lodo 3 & $13,42 \mathrm{c}$ & $9,62 \mathrm{c}$ & $3,80 \mathrm{bc}$ \\
Lodo 4 & $18,50 \mathrm{~b}$ & $16,34 \mathrm{~b}$ & $2,16 \mathrm{~cd}$ \\
Lodo 5 & $20,23 \mathrm{~b}$ & $19,38 \mathrm{~b}$ & $0,85 \mathrm{~d}$ \\
CV (\%) & 21,34 & 25,84 & 36,51 \\
\hline
\end{tabular}

Médias seguidas da mesma letra não diferem estatisticamente pelo teste de Duncan a $5 \%$. Doses de lodo em $\mathrm{g} \mathrm{kg}^{-1}: 1-2,15 ; 2$ 4,31; 3- 8,62; 4- 12,93; 5- 17,24.

A alta mineralização observada no tratamento NPK está relacionado à natureza das fontes de $\mathrm{N}$ aplicadas nesses tratamentos. A ureia, fonte de $\mathrm{N}$ usada no tratamento NPK, por meio da urease, é rapidamente transformada para a forma amoniacal, enquanto no caso dos lodos, materiais orgânicos, a mineralização ocorre lentamente, à medida que o material vai se degradando. Pode-se verificar que o lodo de parboilização de arroz incorporou ao solo, nas doses dos tratamentos de 3 a 7, respectivamente, 204, 409, 819, 1.230 e $1.638 \mathrm{mg}$ de $\mathrm{N}$ orgânico, dos quais 4,12; 1,$7 ; 1,64 ; 1,50 ;$ e $1,23 \%$ foram mineralizados, respectivamente. Observou-se que a mineralização do lodo foi lenta, mesmo este tendo apresentado baixa relação $\mathrm{C} / \mathrm{N}(6 / 1)$, o que pode ser devido ao curto tempo de incubação (59 dias) - período que pode não ter sido suficiente para que o lodo fosse totalmente mineralizado. Castilhos et al. (2002) observaram que $45 \%$ do N orgânico incorporado por meio de lodo de curtume com cromo com relação C/N 7:1 foi mineralizado após 366 dias de incubação.

\section{Biomassa microbiana (carbono e nitrogênio)}

A aplicação do lodo provocou, em média, aumento significativo nos valores de C microbiano do solo, quando comparados aos do tratamento testemunha $\mathrm{e}$ do tratamento com adubação NPK calcário (Figura 2). Os maiores teores de $\mathrm{C}$ microbiano foram observados com a aplicação das doses dos tratamentos 4 e 5 do lodo. A diferença entre os teores de $\mathrm{C}$ microbiano dos tratamentos NPK e testemunha não foi significativa.

Os teores de $\mathrm{N}$ microbiano do solo também aumentaram significativamente com as doses do lodo (Figura 3), quando comparados aos do tratamento testemunha e da adubação NPK. Os teores de N total e N microbiano do solo apresentaram correlação linear simples, com $\mathrm{r}=0,82(\mathrm{p}<0,01)$, evidenciando dependência entre essas variáveis.

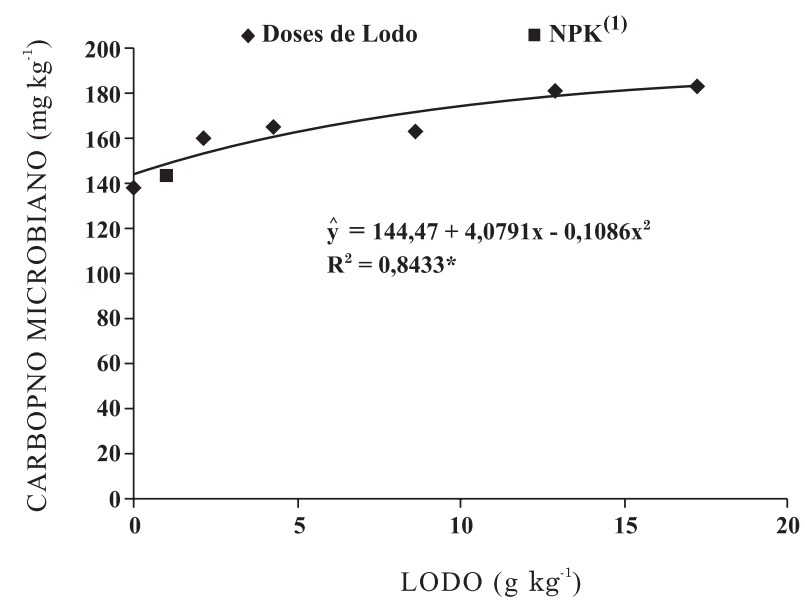

Figura 2. Análise de regressão dos teores de C microbiano no solo após a aplicação de lodo anaeróbio da estação de tratamento de efluentes da parboilização do arroz. "Significativo a $5 \%$. (1) Tratamento NPK incluído como referência fora da análise de regressão.

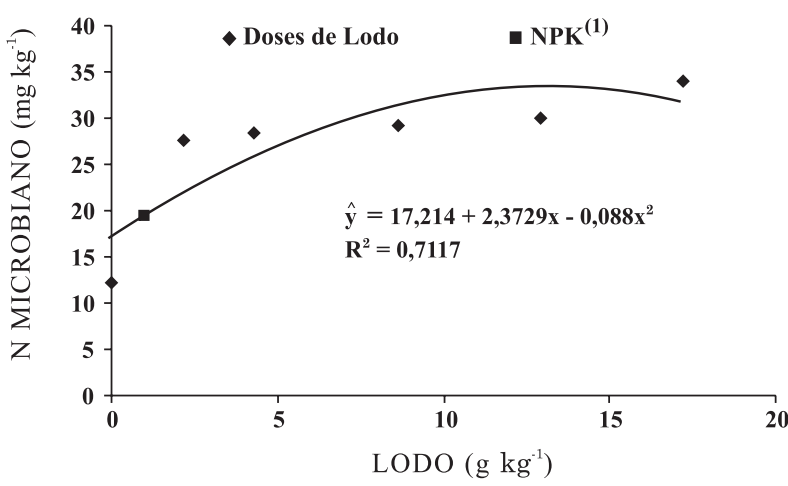

Figura 3. Variação dos teores de nitrogênio microbiano no solo em função da aplicação de lodo anaeróbio da estação de tratamento de efluentes da parboilização do arroz. "Significativo a 5 \%. ${ }^{(1)}$ Tratamento NPK incluído como referência fora da análise de regressão.

O aumento nos teores de $\mathrm{C}$ microbiano com a adição do lodo, provavelmente, ocorreu devido ao aumento do C orgânico no solo, provocado pela adição do lodo. As doses de lodo incorporaram ao solo 1,$29 ; 2,58 ; 5,16$; 7,74; e 10,32 $\mathrm{g} \mathrm{kg}^{-1}$ de C. A correlação linear simples entre os valores de C orgânico e C microbiano apresentou $\mathrm{r}=0,86(\mathrm{p}<0,01)$.

\section{Atividade microbiana}

A atividade microbiana (liberação de $\mathrm{CO}_{2}$ ) aumentou com o incremento das doses do lodo, atingindo o maior valor com a aplicação da maior dose do lodo (Figura 4). A aplicação do lodo também conferiu uma atividade microbiana estatisticamente 


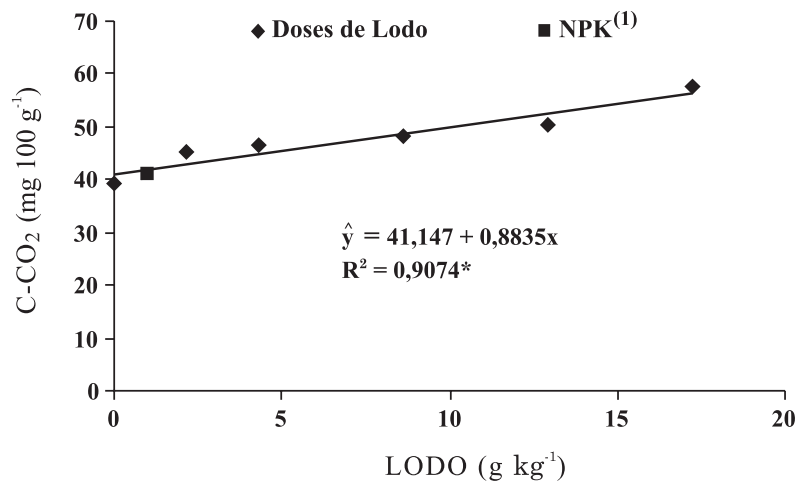

Figura 4. Liberação acumulada de $\mathrm{CO}_{2}$ em solo acrescido de lodo anaeróbio da estação de tratamento de efluentes da parboilização do arroz, durante 50 dias de incubação. "Significativo a $5 \% .{ }^{(1)}$ Tratamento NPK incluído como referência fora da análise de regressão.

superior à constatada nos tratamentos NPK e testemunha (Quadro 3).

$\mathrm{O}$ aumento da atividade microbiana com a aplicação de lodo é também decorrente da maior disponibilidade de $\mathrm{C}$ orgânico para a microbiota do solo, quando comparado à testemunha. Constatou-se correlação linear simples entre os valores de $\mathrm{C}$ orgânico e a liberação de $\mathrm{CO}_{2}$ com $\mathrm{r}=0,78(\mathrm{p}<0,01)$. A atividade microbiana foi mais expressiva nos primeiros 10 dias de incubação, ocorrendo, após, decréscimo na liberação de $\mathrm{C}-\mathrm{CO}_{2}$, provavelmente devido à diminuição do $\mathrm{C}$ prontamente oxidável. A elevada concentração de Mn observada no lodo em estudo (Quadro 1) conduz à necessidade de monitoramento dos teores desse elemento no solo em decorrência de aportes desse resíduo, para que não ocorram níveis tóxicos no solo.

Resultados semelhantes foram relatados por Passianoto et al. (2001) e Konrad \& Castilhos (2002), os quais verificaram acréscimo na produção de $\mathrm{CO}_{2}$ com o aumento das doses de lodos de curtume aplicados ao solo, não ocorrendo em nenhuma das doses inibição do processo respiratório, mesmo com a dose mais elevada do lodo. Observou-se que a biodegradação do $\mathrm{C}$ incorporado nas doses do lodo diminuiu com o aumento das doses aplicadas (Quadro 3).

\section{Quociente metabólico ( $\left.\mathrm{qCO}_{2}\right)$}

De modo geral, a aplicação do lodo determinou valores de qCO2 significativamente mais baixos que os obtidos nos tratamentos NPK + calcário e testemunha (Quadro 4).

Com exceção da dose máxima, as demais doses do lodo conferiram ao solo os menores valores de $\mathrm{qCO}_{2}$, não havendo diferença significativa entre si. O menor $\mathrm{qCO}_{2}$ nesses tratamentos indica que menos $\mathrm{C}$ foi perdido como $\mathrm{CO}_{2}$ pela respiração e uma maior porção de $\mathrm{C}$ foi incorporada aos tecidos microbianos, como resultado da ação de uma biomassa "eficiente" atuando sobre o lodo adicionado ao solo. O tratamento adubação NPK seguido do tratamento testemunha apresentaram os maiores valores de $\mathrm{qCO}_{2}$, revelando baixa eficiência da população microbiana nos tratamentos em que não houve aporte de material orgânico. Segundo Sakamoto (1994), um baixo quociente metabólico indica economia na utilização de energia e a eficiência da biomassa microbiana em utilizar o $\mathrm{C}$ disponível para biossíntese e, supostamente, reflete um ambiente mais estável ou mais próximo do ambiente de equilíbrio. Valores elevados são indicativos de ecossistemas submetidos a alguma condição de estresse.

\section{Relações químicas e microbianas}

Os valores da relação C orgânico e $\mathrm{N}$ totais (COT/ NT) nos tratamentos com aplicação de lodo anaeróbio da estação de tratamento de efluentes da parboilização de arroz foram significativamente superiores aos do tratamento testemunha (Quadro 5). Com o aumento das doses de lodo, a relação COT/NT apresentou declínio em decorrência do aumento nos teores de $\mathrm{N}$ total com o crescimento das doses (Quadro 5).

A relação $\mathrm{C}$ e $\mathrm{N}$ microbianos $(\mathrm{CM} / \mathrm{NM})$ não diferiu estatisticamente entre as doses do lodo aplicado. Esses

Quadro 3. Carbono adicionado, liberação como $\mathrm{CO}_{2}$ e biodegrado no solo durante 50 dias de incubação após a aplicação de lodo anaeróbio da estação de tratamento de efluentes da parboilização do arroz

\begin{tabular}{|c|c|c|c|c|}
\hline Tratamento & $\mathrm{C}$ adicionado via lodo & Liberação & C biodegradado & Taxa de biodegradação ${ }^{(1)}$ \\
\hline & mg $100 \mathrm{~g}^{-1} \mathrm{C}$ no solo & \multicolumn{2}{|c|}{$-\mathrm{mg} 100 \mathrm{~g}^{-1} \mathrm{C}-\mathrm{CO}_{2}$ no solo — } & $\%$ \\
\hline Testemunha & 0 & $39,06 \mathrm{e}$ & 58,59 & - \\
\hline NPK & 0 & $40,86 \mathrm{e}$ & - & - \\
\hline Lodo 1 & 34 & $45,06 \mathrm{~d}$ & 67,59 & 26,47 \\
\hline Lodo 2 & 67,86 & $46,56 \mathrm{~cd}$ & 69,84 & 16,75 \\
\hline Lodo 3 & 135,73 & $48,06 \mathrm{bc}$ & 72,09 & 10,05 \\
\hline Lodo 4 & 203,74 & $50,46 \mathrm{~b}$ & 75,69 & 8,48 \\
\hline Lodo 5 & 271,60 & $57,66 \mathrm{a}$ & 86,49 & 10,38 \\
\hline $\mathrm{CV}(\%)$ & - & 3,9 & & - \\
\hline
\end{tabular}


Quadro 4. Quociente metabólico do solo após 59 dias de incubação com a aplicação de lodo anaeróbio da estação de tratamento de efluentes da parboilização de arroz

\begin{tabular}{lc}
\hline Tratamento & Quociente metabólico \\
\hline & $\mathrm{qCO}_{2} \times 10^{-3}$ \\
Testemunha & $2,33 \mathrm{~b}$ \\
NPK & $3,08 \mathrm{a}$ \\
Lodo 1 & $2,04 \mathrm{c}$ \\
Lodo 2 & $2,05 \mathrm{c}$ \\
Lodo 3 & $2,09 \mathrm{c}$ \\
Lodo 4 & $2,09 \mathrm{c}$ \\
Lodo 5 & $2,34 \mathrm{~b}$ \\
CV $(\%)$ & 4,33
\end{tabular}

Médias seguidas da mesma letra não diferem estatisticamente pelo teste de Duncan a $5 \%$. Doses de lodo em $\mathrm{g} \mathrm{kg}^{-1}: 1$ - 2,15; 2 4,$31 ; 3-8,62 ; 4-12,93 ; 5-17,24$.

Quadro 5. Relações C orgânico e nitrogênio totais (COT/NT), C e nitrogênio microbianos (CM/NM), C microbiano e C orgânico total (CM/COT) e nitrogênio microbiano e nitrogênio total (NM/ NT) em solo acrescido de lodo anaeróbio da estação de tratamento de efluentes da parboilização de arroz

\begin{tabular}{lccccc}
\hline \multirow{2}{*}{ Tratamento } & COT/NT & CM/NM & CM/COT & NM/NT \\
\cline { 2 - 3 } \cline { 5 - 6 } Testemunha & $9,9 \mathrm{e}$ & $11,9 \mathrm{a}$ & & $2,2 \mathrm{a}$ & $1,9 \mathrm{c}$ \\
NPK & $10,7 \mathrm{~d}$ & $7,4 \mathrm{~b}$ & & $1,9 \mathrm{~b}$ & $2,8 \mathrm{~b}$ \\
Lodo 1 & $13,4 \mathrm{~b}$ & $5,8 \mathrm{bc}$ & $1,6 \mathrm{c}$ & $3,7 \mathrm{a}$ \\
Lodo 2 & $14,6 \mathrm{a}$ & $5,9 \mathrm{bc}$ & $1,5 \mathrm{c}$ & $3,7 \mathrm{a}$ \\
Lodo 3 & $13,4 \mathrm{~b}$ & $5,6 \mathrm{bc}$ & $1,5 \mathrm{c}$ & $3,5 \mathrm{a}$ \\
Lodo 4 & $12,6 \mathrm{c}$ & $6,1 \mathrm{bc}$ & $1,6 \mathrm{c}$ & $3,4 \mathrm{a}$ \\
Lodo 5 & $10,9 \mathrm{~d}$ & $5,4 \mathrm{c}$ & $1,6 \mathrm{c}$ & $3,3 \mathrm{ab}$ \\
CV (\%) & 4,2 & 17,8 & & 6,0 & 10,5 \\
\hline
\end{tabular}

Médias seguidas da mesma letra não diferem estatisticamente pelo teste de Duncan a $5 \%$. Doses de lodo em $\mathrm{g} \mathrm{kg}^{-1}: 1$ - 2,15; 2 4,$31 ; 3-8,62 ; 4-12,93 ; 5-17,24$.

valores, com exceção da dose referente ao tratamento 5, também não diferiram da relação observada no tratamento com adubação NPK (Quadro 5). Observouse diminuição na relação $\mathrm{CM} / \mathrm{NM}$ entre as duas maiores doses aplicadas do lodo, possivelmente devido ao fato de que o aumento nos teores de $\mathrm{C}$ microbiano foi proporcionalmente inferior ao aumento nos teores de $\mathrm{N}$ microbiano do solo, fazendo com que a relação $\mathrm{CM} / \mathrm{NM}$ diminuísse entre as doses referentes aos tratamentos 4 e 5 .

Nos tratamentos com o lodo, a relação $\mathrm{C}$ microbiano e C orgânico total (CM/COT) apresentou valores significativamente inferiores aos dos tratamentos testemunha e adubação NPK, não havendo diferença significativa entre as doses do lodo. Em termos médios, a diminuição nesses tratamentos foi de 28 e $18 \%$ quando comparados aos tratamentos testemunha e NPK. Com o aumento das doses do lodo, ocorreu diminuição na relação CM/COT, não havendo diferença significativa entre as doses. A relação NM/NT mostrou aumento signficativo nos tratamentos com lodo em comparação com a testemunha, porém entre as doses do lodo não houve diferença estatística. As relações $\mathrm{CM} / \mathrm{COT}$ e NM/NT expressam índices da qualidade nutricional da matéria orgânica. Para solos com matéria orgânica de baixa qualidade nutricional, a biomassa microbiana encontra-se sob condições de estresse, diminuindo a capacidade de utilizar o $\mathrm{N}$ e o $\mathrm{C}$ orgânico; com isso, as relações CM/COT e NM/NT diminuem. Entretanto, a biomassa microbiana poderá aumentar rapidamente caso ocorra adição de matéria orgânica de boa qualidade nutricional, mesmo que os teores de C orgânico permaneçam inalterados (GamaRodrigues, 1999).

\section{CONCLUSÕES}

1. A atividade microbiana do solo, medida pela liberação de $\mathrm{C}-\mathrm{CO}_{2}$, e a biomassa microbiana, avaliada pelos teores de $\mathrm{C}$ e $\mathrm{N}$, assim como os teores de $\mathrm{C}$ orgânico do solo, aumentaram com as doses de lodo anaeróbio da estação de tratamento de efluentes da parboilização do arroz e proporcionaram diminuição no quociente metabólico do solo.

2. A aplicação do lodo não alterou as relações $\mathrm{C}$ orgânico e $\mathrm{N}$ totais, $\mathrm{C}$ e $\mathrm{N}$ microbianos, $\mathrm{C}$ microbiano e C orgânico total e $\mathrm{N}$ microbiano e total, quando comparados ao tratamento com adubação NPK.

3. O lodo testado pode ser aplicado ao solo, em doses recomendadas, com benefícios à atividade e à biomassa microbiana do solo.

\section{LITERATURA CITADA}

ALEF, K. \& NANNIPIERI, P. Methods in applied soil microbiology and biochemistry. London, Academic Press, 1995. $576 \mathrm{p}$.

ANDERSON, T.H. \& DOMSCH, K.H. Application of ecophysiological quociente (qCO2 and $\mathrm{Dq}$ ) on microbial biomasses from soils of different cropping histories. Soil Biol. Biochem., 22:251-255, 1990.

ARAÚJO, A.S.F. \& MONTEIRO, R.T.R. Microbial biomass and activity in a Brazilian soil plus untreated and composted textile sludge. Chemosphere, 64:1043-1046, 2006.

BETTIOL, W. \& FERNANDES, S.A.P. Efeito do lodo de esgoto na comunidade microbiana e atributos químicos do solo. Jaguariúna, Embrapa Meio Ambiente, 2004. (Comunicado Técnico)

BROOKES, D.C. The use of microbial parameters in monitoring soil pollution by heavy metals. Biol. Fert. Soils, 19:269-279, 1995 . 
CARDOSO, E.J.B.N. \& FORTES. N.P. Aplicabilidade do biossólido em plantações florestais: Alterações microbianas no solo. In: BETTIOL, W. \& CAMARGO, O.A., orgs. Impacto ambiental do uso agrícola do lodo de esgoto. Jaguariúna, Embrapa Meio Ambiente, 2000. p.197-202.

CASTILHOS, D.D.; TEDESCO, M.J. \& VIDOR, C. Rendimento de culturas e alterações químicas do solo tratado com resíduos de curtume e cromo hexavalente. R. Bras. Ci. Solo, 26:1083-1092, 2002

COMISSÃO DE QUÍMICA E FERTILIDADE DO SOLO CQFS/NRS. Manual de adubação e de calagem para os Estados do RS e SC. 10.ed. Porto Alegre, Sociedade Brasileira de Ciência do solo - Núcleo Regional Sul, 2004. $394 p$.

DICK, R.P. Soil enzyme assays as indicators of soil quality. In: DORAN, J.W.L.; COLEMAN, D.C.; BEZDICEK, D.F. \& STEWART, B.A. eds. Defining soil quality for a sustainable enviroment. Madison, Soil Science Society of America, 1994. p.107-124.

EMPRESA BRASILEIRA DE PESQUISA AGROPECUÁRIA EMBRAPA. Centro Nacional de Pesquisa em Solos. Sistema brasileiro de classificação de solos. Brasília, Produção de Informação; Rio de Janeiro, Embrapa Solos, 1999. $412 \mathrm{p}$

FERREIRA, A.S.; CAMARGO, F.A.O. \& VIDOR, C. Utilização de microondas na avaliação da biomassa microbiana do solo. R. Bras. Ci. Solo, 23:991-996, 1999.

GAMA-RODRIGUES, E.F. Biomassa microbiana e ciclagem de nutrientes. In: SANTOS, G.A. \& CAMARGO, F.A.O Fundamentos da matéria orgânica do solo, ecossistemas topicais \& subtropicais. Porto Alegre, Gênesis, 1999. p.227243.

GILLER, K.E.; WITTER, E. \& MCGNATH, S.P. Toxicity of heavy metals to microorganisms and microbial processes in agriculture soils: A review. Soil Biol. Biochem., 30:1389. 1414,1998

JENKINSON, D.S. \& LADD, J.N. Microbial biomass in soil: Measurement and turnover. In: PAUL, E.A. \& LADD, J.N., orgs. Soil biochemistry. New York, Marcel Dekker, 1981. p.415-471.
KONRAD, E.E. \& CASTILHOS, D.D. Alterações químicas do solo e crescimento do milho decorrente da adição do lodo de curtume. R. Bras. Ci. Solo, 26:257-265, 2002.

LAMBAIS, M.R. \& CARMO, J.B. Impacto da aplicação de biossólidos na microbiota de solos tropicais. R. Bras. Ci. Solo, 32:1129-1138, 2008.

MACHADO, A. Sistema de análise estatística para Windows (Winstat). Pelotas, Universidade Federal de Pelotas, 2001.

PASSIANOTO, C.C.; CASTILHOS, D.D.; CASTILHOS, R.M.V.; LIMA, A.C.R. \& LIMA, C.L.R. Atividade e biomassa microbiana no solo com a aplicação de dois diferentes lodos de curtume. R. Bras. Agroc., 7:125-130, 2001.

PAULA, A.M.; SOARES, C.R.F.S. \& SIQUEIRA, J.O. Biomassa, atividade microbiana e fungos micorrízicos em solo de "landfarming" de resíduos petroquímicos. R. Bras. Eng. Agríc. Amb., 10:448-445, 2006.

PROSSER J.L. Microrganisms cycling soil nutrients and their diversity. In: ELSAS, J.D.V., ed. Modern soil microbiology. 2.ed. New York, 2007. p.237-261.

SAKAMOTO, K. \& OBO, Y. Effects of fungal to bacterial ratio on the relationship between $\mathrm{CO}_{2}$ evolution and total soil microbial biomass. Biol. Fert. Soil, 17:39-44, 1994.

STOTZKY, G. Microbial respiration. In: BLACK, C.A. Methods of soil analysis. Madison, Americam Society of Agronomy, 1965. v.2. p.1151-1572.

TEDESCO, M.J.; GIANELLO, C.; BISSANI, C.A.; BOHNEN, H. \& VOLKWEISS, S.J. Análises de solo, plantas e outros materiais. Porto Alegre, Universidade Federal do Rio Grande do Sul, 1995. 1749p.

VANCE, E.D.; BROOKES, P.C. \& JENKINSON, D.S. An extraction method for measuring soil microbial biomass C. Soil Biol. Biochem., 19:703-107, 1987.

VAZ, L.M.S. \& GONÇALVES, J.L.M. Uso de biossólidos em povoamento de Eucalyptus grandis: Efeito em atributos químicos do solo, no crescimento e na absorção de nutrientes. R. Bras. Ci. Solo, 26:747-758, 2002. 